\title{
A study on promotion method of effective initiatives for establishment of the Integrated Community Care System
}

\author{
Shinki FURUKAWA*1, Chisato KAJIHARA ${ }^{2}$, \\ Akira SHINDO $^{3}$, Masahiko MUNECHIKA ${ }^{1}$ \\ ${ }^{1}$ Waseda University, Tokyo, Japanese Society for Quality Control, JSQC (Japan), \\ ${ }^{2}$ Shizuoka University, Shizuoka, Japanese Society for Quality Control, JSQC (Japan), \\ ${ }^{3}$ Oguno Hospital, Tokyo, Japanese Society for Quality Control, JSQC (Japan), \\ *ko-o@akane.waseda.jp
}

\begin{abstract}
:
In Japan, the rapidly aging population has led to a demand for seamless medical and long-term care services to elderly. Given this situation, the Ministry of Health, Labor and Welfare aims to promote an Integrated Community Care System that can appropriately provide various services. This system requires the cooperation of all relevant organizations in the community, such as hospitals, nursing facilities, and pharmacies. Although each community is working toward strengthening cooperation, effective ways to promote concrete initiatives are still unclear. The increasing interest in the Integrated Community Care System has led to pioneering cases, but they are difficult to replicate in communities handicapped by insufficient resources. Therefore, each community need to promote initiatives based on regional characteristics.

The purpose of this study is to propose a method to promote such initiatives effectively. First, we list the activities required to establish the Integrated Community Care System and construct a model to put it in place. We then assess the present level of cooperation in a community (which we identify as Community A) and estimate its resources. We then develop a roadmap for the establishment of the System. Furthermore, we identify some effective initiatives and try to implement them in Community A.
\end{abstract}

\section{Keywords}

Integrated Community Care System, Promotion method of initiatives, Model of management system, Roadmap

\section{Introduction}

In Japan, where the society is aging at an unprecedented rate, it is estimated that the proportion of the elderly to the total population will exceed $30 \%$ by 2025 . In such a society, older patients will account for a majority of medical care. The elderly patient often suffers from multiple chronic diseases, and even after short-term treatment, has difficulty in returning to the original state of health, before the onset of disease. Therefore, patients need to continue to receive treatment at multiple medical institutions and related facilities depending on their condition. Under such circumstances, it is important that organizations in the community cooperate with each other to provide seamless medical and long-term care services. To this end, the Ministry of Health, Labour and Welfare is promoting the establishment of an Integrated Community Care System that can appropriately offer various support services across different aspects of daily life. Therefore, each community aims at strengthening the level of cooperation among institutions and other service providers.

For the establishment of such a system, each community needs to promote initiatives directed toward strengthening cooperation. Therefore, it is necessary to clarify the areas in which the level of cooperation remains insufficient within the community and provide relevant support. However, the specific initiatives that suit the community have not been promoted, since certain features and issues of the community have not been understood. In addition, while increasing interest in the Integrated Community Care System has led to pioneering cases, they are difficult to replicate in communities handicapped by insufficient resources. Therefore, 
it is necessary to decide on a set process-including understanding the present state and planning accordingly — and to promote initiatives based on the specific features and issues of the community. Understanding the features and issues of the community and establishing methods for promoting the initiatives best suited to the community become key issues in the establishment of an Integrated Community Care System.

The purpose of this study is to propose a method for promoting effective initiatives based on the objectives of each community for the establishment of an Integrated Community Care System.

\section{Previous studies and research approach}

\subsection{Previous studies}

Yamamoto et al. (2014) examined and proposed issues and measures for cooperation promotion in the construction of an Integrated Community Care System. At that time, this study showed 5 important issues such as "Promotion of business standardization and efficiency" and "Construction and operation of PDCA system" from the result of fact-finding survey conducted for persons in charge in Aichi Prefecture. As measures for the issues, 4 measures such as "Use of management systems engineering techniques" and "Development of an evaluation system" are proposed.

However, the fact-finding survey was conducted for the staff of the community general support center, and the actual condition of other relevant organizations was not considered. The design and analysis of the survey were not carried out by the established method, and issues and measures are examined using the qualitative data. In addition, since the concrete measures are not shown, it cannot be actually utilized in each region.

YAMAZAKI (2017) extracted community issues in the establishment of an Integrated Community Care System based on the difference between the ideal condition and the present state. To begin with, the study clarifies the necessary care for a community (which they identify as Community A) and then determines the ideal state by examining the role of each organization. A questionnaire survey was designed to quantitatively assess the present state of the community, and it was administered in 12 types of relevant organizations.

However, it is not clear what kinds of objectives should be set for the community, and what kind of initiatives should be advanced to establish the Integrated Community Care System. Therefore, only the analysis of the survey results has been carried out, and the establishment of the Integrated Community Care System utilizing them has not been promoted.

\subsection{Research approach}

This study examines the model which shows the whole picture of the establishment of the Integrated Community Care System. We first list the activities required to establish the Integrated Community Care System including grasp of the present state and execution of the initiative. On the basis of this, we create the model to the realization of the final goal of the Integrated Community Care System. In addition, we examine the phase which shows the progress to the final goal. In order to promote the establishment based on these examinations, we then develop a common road map with general initiatives to be made in each phase.

After that, we grasp the situation of resources and cooperation of community A, and then set the objective which matches the community, and derive the high priority challenge. Moreover, we draw up a roadmap specific to community, showing the process of promoting the initiative, and partially implement it for Community A.

Finally, we summarize the knowledge obtained in the process and propose a method to promote the establishment of an Integrated Community Care System.

\section{Examination of the promotion method}

\subsection{Extraction of necessary activities}

In order to examine the process of establishment of the Integrated Community Care System, we first listed the activities required to establish the system. In this regard, we analyzed 18 pioneering cases of Integrated Community Care Systems, project plans, and conference minutes of multiple municipalities. Based on the extracted activities, we developed concrete items to be carried out in the advancement of each activity and classified them into 10 components. The results are shown in Table 1. 
Total Quality Science Vol.6, No.3

Table 1: Activities required in building Integrated Community Care System

\begin{tabular}{|c|c|c|}
\hline Components & Activities required & Concrete items \\
\hline \multirow{5}{*}{$\begin{array}{l}\text { 1. Identification of care } \\
\text { required }\end{array}$} & \multirow{2}{*}{ 1-1)Consideration of care for avoiding incidents } & 1-1-1)Consideration of care required for patients' independence \\
\hline & & 1-1-2)Identify resources required for the care stated above \\
\hline & \multirow{3}{*}{ 1-2)Consideration of care after incidents occur } & 1-2-1)Consideration of treatment required in an emergency \\
\hline & & 1-2-2)Consideration of measures to prevent patient abuse \\
\hline & & 1-2-3)Identify resources required for the care stated above \\
\hline \multirow{10}{*}{$\begin{array}{l}\text { 2. Assessment of the } \\
\text { community's circumstances }\end{array}$} & \multirow{4}{*}{$\begin{array}{l}\text { 2-1)Setting the scope of Integrated Community } \\
\text { Care System }\end{array}$} & 2-1-1)Setting target community \\
\hline & & $\begin{array}{l}\text { 2-1-2)Setting target community businesses (healthcare, caregiving, livelihood } \\
\text { support/care prevention) }\end{array}$ \\
\hline & & 2-1-3)Setting the scope of stakeholders to be taken into account \\
\hline & & 2-1-4)Setting the scope of the target businesses \\
\hline & \multirow{2}{*}{$\begin{array}{l}\text { 2-2)Assess resources and programs in the } \\
\text { target community }\end{array}$} & 2-2-1)Understand the program description (services, bases, competencies) \\
\hline & & 2-2-2)Understand structure of the program \\
\hline & \multirow{3}{*}{$\begin{array}{l}\text { 2-3)Assess needs and expectations of the local } \\
\text { residents/stakeholders }\end{array}$} & 2-3-1)Understand the needs and expectations of local residents \\
\hline & & 2-3-2)Understand the needs and expectations of staff \\
\hline & & 2-3-3)Understand the needs and expectations of partners \\
\hline & 2-4)Understand laws and regulations & $\begin{array}{l}\text { 2-4-1)Understand the Long-term Care Insurance Act and Medical Care and } \\
\text { Nursing Care Cooperation Promotion Project }\end{array}$ \\
\hline \multirow{6}{*}{ 3. Objective setting } & \multirow{2}{*}{ 3-1)Examinination of current circumstances } & 3-1-1)Share the result of \#1 with the stakeholders in the community \\
\hline & & 3-1-2)Understand the circumstances \\
\hline & \multirow{2}{*}{ 3-2)Objective setting } & 3-2-1)Consider the ideal state \\
\hline & & 3-2-2)Consider KGI \\
\hline & \multirow{2}{*}{ 3-3)Share objectives } & 3-3-1)Share the ideal state with the stakeholders in the community \\
\hline & & 3-3-2)Share the indicators to be improved \\
\hline \multirow{3}{*}{ 4. Identification of issues } & 4-1)Identification of needs & 4-1-1)Identify needs and care required in the community \\
\hline & 4-2)Identification of capacity & 4-2-1)Identify existing competencies to fulfill the needs \\
\hline & $\begin{array}{l}\text { 4-3)Examination of disparity between needs and } \\
\text { capacity }\end{array}$ & 4-3-1)Identify disparity between needs and competencies \\
\hline \multirow{4}{*}{$\begin{array}{l}\text { 5. Derive initiatives for } \\
\text { issues }\end{array}$} & 5-1)Understand cause of the issue & 5-1-1)Investigate causes of issues to take countermeasures \\
\hline & 5-2)Consider effective approaches & 5-2-1)Consider suitable directions for the measures \\
\hline & \multirow{2}{*}{ 5-3)Operation/work environment } & 5-3-1)Research measures taken against similar issues in other communities \\
\hline & & 5-3-2)Consider feasible and effective initiatives \\
\hline \multirow{4}{*}{$\begin{array}{l}\text { 6. Formulation of plan of } \\
\text { introduction }\end{array}$} & \multirow{4}{*}{$\begin{array}{l}\text { 6-1)Formulation of detailed introduction and } \\
\text { operation process }\end{array}$} & 6-1-1)Consider course of action and process for the measure \\
\hline & & 6-1-2)Consider management resources and organizational structure \\
\hline & & 6-1-3)Consider roles of each organization \\
\hline & & 6-1-4)Document the details considered above \\
\hline \multirow{7}{*}{$\begin{array}{l}\text { 7. Introduce and promote } \\
\text { initiatives }\end{array}$} & \multirow{3}{*}{ 7-1)Leadership } & 7-1-1)Select leader for the initiative \\
\hline & & 7-1-2)Put the initiative into shape and disseminate \\
\hline & & 7-1-3)Request cooperation from each organization \\
\hline & \multirow{2}{*}{ 7-2)Introduction of initiatives } & 7-2-1)Devote resources required \\
\hline & & 7-2-2)Pursue role of each organization \\
\hline & & 7-3-1)Assess status of initiative implementation \\
\hline & 7-3)Promotion of initiatives & $\begin{array}{l}\text { 7-3-2)Understand past examples of bottlenecks and difficulties and eliminate } \\
\text { them }\end{array}$ \\
\hline & 8-1) Sustaining initiatives & 8-1-1)Consider a method to control the initiatives \\
\hline Q Anplication of initiativec & 8-1)sustaining initlatives & 8-1-2)Set up surveillance system for the initiatives \\
\hline 8. Applicatıon of Initiatıves & 8-2)Fynanding crone of initiatives & 8-2-1)Establish instructional system \\
\hline & 8-2) Expanaing scope of inilialives & 8-2-2)Raise public awareness \\
\hline & & 9-1-1)Report the status of initiatives \\
\hline & 9-1)Measuring achievements & 9-1-2)Investigate effectiveness of the initiatives \\
\hline 9. Measurement of & & $\begin{array}{l}\text { 9-1-3)Compare the ideal state and the state of the community after } \\
\text { implementation of the initiatives }\end{array}$ \\
\hline & & 9-2-1)Make sure the care is adequately carried out \\
\hline & 9-2)Measuring fulfillment & $\begin{array}{l}\text { 9-2-2)Make sure surveillance system is established for maintenance of } \\
\text { dignity }\end{array}$ \\
\hline & & $\begin{array}{l}\text { 10-1-1)Investigate if Integrated Community Care System improved the } \\
\text { situation of the commnunity }\end{array}$ \\
\hline & 10-1)Identification of suboptimal points & $\begin{array}{l}\text { 10-1-2)Investigate if needs and output (community where patients can build } \\
\text { their lifestyle) are sufficient }\end{array}$ \\
\hline & & 10-2-1)Review methods to assess the circumstances of the community \\
\hline 10. Improvement of system & & 10-2-2)Review needs \\
\hline & & 10-2-3)Review care required \\
\hline & 10-2)Considering points of improvement & 10-2-4)Review details of the initiatives \\
\hline & & 10-2-5)Review operational process of the initiatives \\
\hline & & 10-2-6)Review measuring method of effectiveness \\
\hline
\end{tabular}

From the information presented in Table 1, we organize what should be carried out independently by the community so it can be understood systematically. 


\subsection{Creating a Model}

It is effective and efficient to operate the Integrated Community Care System as a management system that aims at developing a better mechanism through continuous improvement. Referring to the model of the Area Disaster Resilience Management System for Healthcare that proposed by Kajihara et al. (2019), a community-focused management system, we examined the mutual relationship of the components and arranged them in the form of a management system.

We constructed the model in line with the definition of the Integrated Community Care System, as proposed by the Ministry of Health, Labour and Welfare: “A system in which housing, medical care, long-term care, prevention, and livelihood support are provided in an integrated manner so that a person can continue to live his or her own life to the end in the area where he or she has become accustomed to living even if in a severe condition requiring long-term care.” Our model is shown in Figure 1.

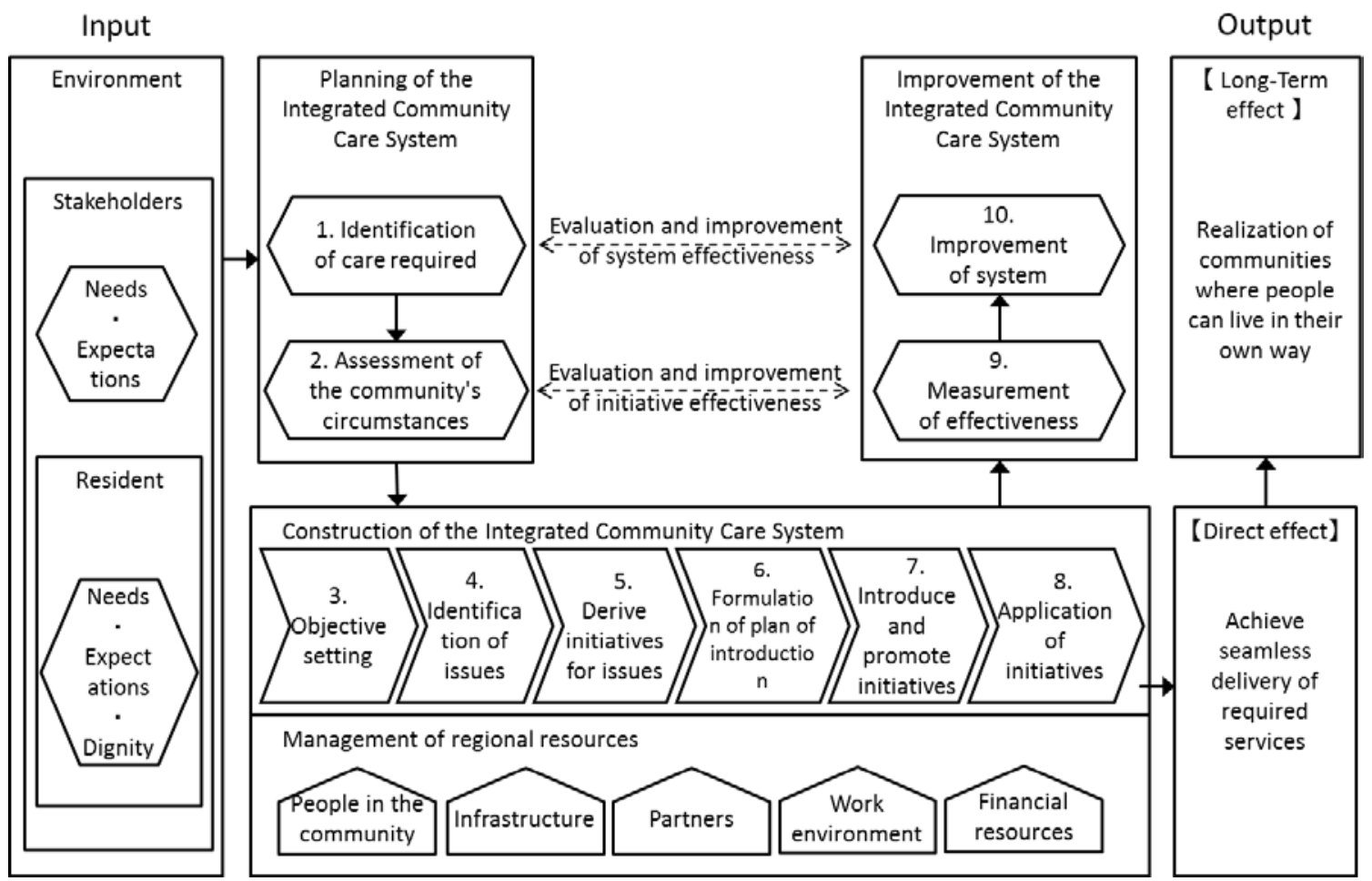

Figure 1: Model of Integrated Community Care System

As shown in Figure 1, 10 components which written in hexagon or chevron diagram were classified into 3 stages such as planning, construction and improvement of the Integrated Community Care System. Then, the system is established with "Environment surrounding the community" on the left side of the figure as an input, and the realization of "Achieve seamless delivery of required services" on the right side of the figure is obtained as an output. And it leads to the "realization of communities where people can live in their own way" which is the final goal of the System. In addition, since resources are necessary in order to surely carry out these, we described the operation management of regional resources which written in pentagon as a basis of the model.

\subsection{Development of a roadmap}

\subsubsection{Concept of the roadmap}

In 3.2, a model of the Integrated Community Care System was visualized. In the construction stage, in particular, it is necessary to establish the common goal of the community based on the state of the community, share it among the parties concerned, and make and execute the plan for its achievement. Then, as a tool for the effective execution of this stage, we developed the construction roadmap of the Integrated Community Care System. This makes it possible to grasp the initiatives and direction by showing the objectives of the community and sharing it among municipalities. 


\subsubsection{Understanding the state of the community}

It is first necessary to understand the state of the community in order to decide its future direction. YAMAZAKI (2017) designed her questionnaire for assessing the community's present state in the establishment of the Integrated Community Care System. After examining the level and type of care necessary for the community's comprehensive care system, the answers to questions such as "Is the Patient's Intention Respected?”, and “Do they share a concrete image of the Integrated Community Care System?” are deduced, and each achievement is measured. The survey was carried out for 12 types of organizations, including hospitals, nursing facilities, and pharmacies, and responses were received from 262 organizations.

In this study, we used the results of the survey carried out by YAMAZAKI to understand the state of Community A. We also referred to the progress of the project plan of the target municipalities. This allowed us to better understand the present state of Community A and obtain clarification for statements such as "The medical treatment that the patient desires is not clear, and the selection of the medical treatment that meets the patient's wishes is difficult."

\subsubsection{Establishment of objectives and derivation of initiatives}

It is important to set the objective when promoting the initiatives. However, it is difficult to determine a unique ideal state, and even if a vague objective is set, it is difficult to move the initiatives forward.

As a next step, we divided the state of the community into several viewpoints and examined the objective to be achieved based on each viewpoint. We used eight topics from the "Medical Care and Nursing Care Cooperation Promotion Project”, a project promoted by the Ministry of Health, Labour and Welfare (2017) for the establishment of Integrated Community Care Systems across the country. As a result, for Community A, we established the objective of "Medical care is chosen according to the patient's wishes."

We then compared the state of community and the objective and extracted issues that could become barriers to realizing the objective. For example, we extracted the issue of "What kind of medical care the patient desires should be clarified in order to realize that medical care is chosen according to the patient's wishes." From this issue, we deduced that a confirmation method of the patient intention should be established.

By clarifying the issues from the objective in this manner, the derivation of the initiatives that match the actual circumstances of the community became possible. Table 2 shows part of the roadmap prepared for Community A.

Table 2: Roadmap for the establishment of the Integrated Community Care System (Partial)

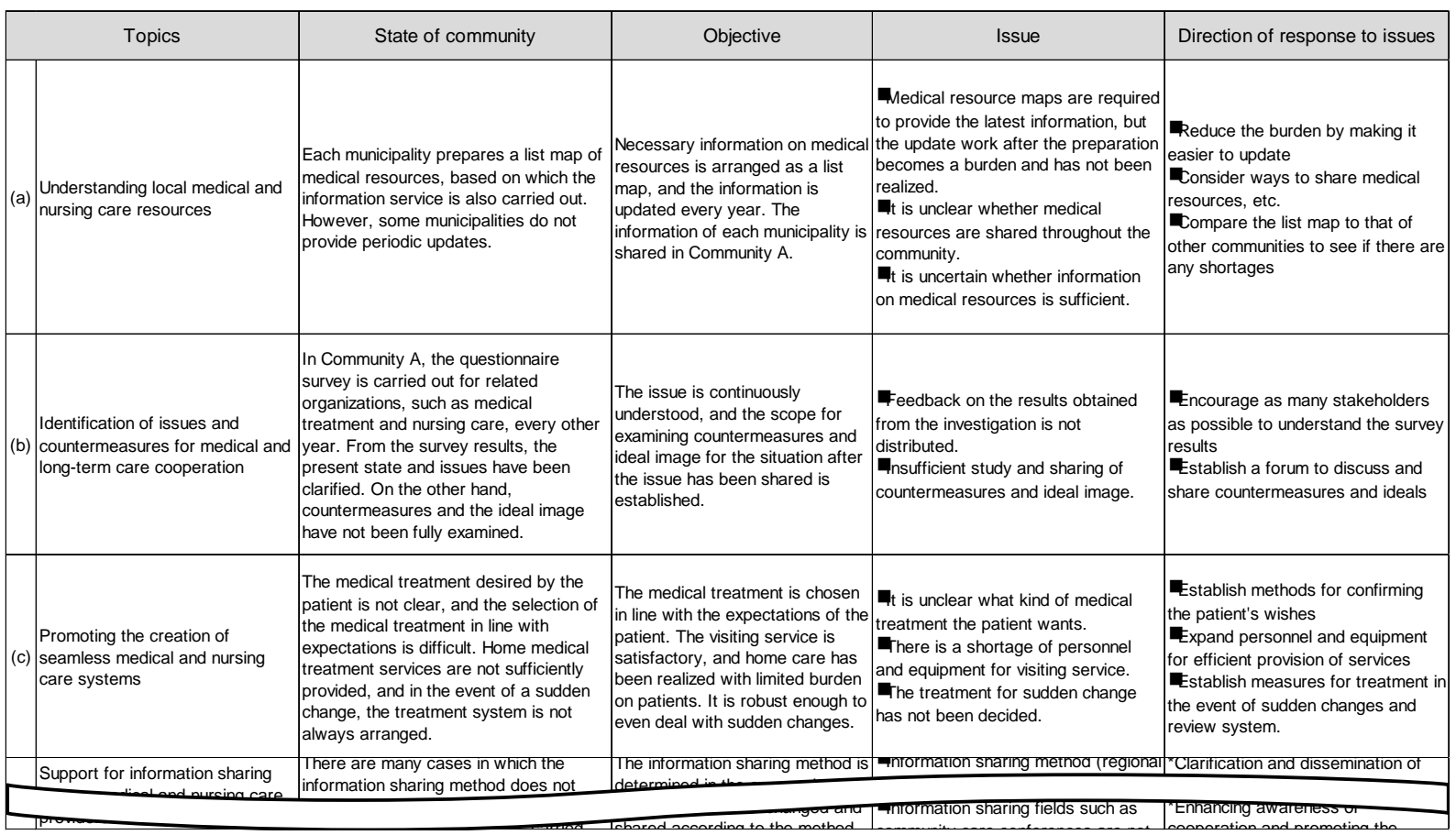




\subsubsection{Review phases of the Integrated Community Care System}

Various issues and corresponding initiatives have been derived in order to establish the Integrated Community Care System. However, it is difficult to work on everything at once because a certain amount of resources is required to carry out the work. In this regard, "priority focused" is mentioned as an important concept in the introduction and promotion of the quality management system used for medical treatment. This means that the solutions should be derived focusing on the most important issues first, and this is considered to be the most appropriate approach, even in the Integrated Community Care System that cannot be constructed in a short period.

Then, we examined the phases of the Integrated Community Care System. This indicates the priority issues to be addressed. By associating it with the prepared roadmap, we can determine the concrete matters to be carried out. In dividing the phases, we applied the common issue and purpose of the Integrated Community Care System, as demonstrated by YAMAZAKI (2017). The results of the phase classification are shown in Table 3.

Table 3: Phases of the Integrated Community Care System

\begin{tabular}{|c|c|c|}
\hline Phase & Target & Requirement \\
\hline $\begin{array}{l}\langle\text { Phase } 0\rangle \\
\text { A state in which a community integrated care provider } \\
\text { can share a concrete image of the system. }\end{array}$ & $\begin{array}{l}\text { Increase awareness and understanding of } \\
\text { the system. }\end{array}$ & $\begin{array}{l}\text { Continue planning, sharing, and reviewing } \\
\text { plans. } \\
\text { Holding W orkshops. }\end{array}$ \\
\hline $\begin{array}{l}\langle\text { Phase } 1\rangle \\
\text { A state in which the community integrated care } \\
\text { provider is aware of the patient's wishes. }\end{array}$ & $\begin{array}{l}\text { Establishment of method to understand } \\
\text { patient's intention. }\end{array}$ & $\begin{array}{l}\text { An environment that can respect the intention } \\
\text { of the patient regarding emergency } \\
\text { transportation. } \\
\text { A mechanism that supports the decisions of the } \\
\text { patient }\end{array}$ \\
\hline $\begin{array}{l}\langle\text { Phase } 2\rangle \\
\text { A state in which an integrated community care } \\
\text { provider is performing each role. }\end{array}$ & Each organization plays its own role. & $\begin{array}{l}\text { Clarification of the care required according to } \\
\text { the patient's condition. } \\
\text { larification of the role each organization should } \\
\text { play. }\end{array}$ \\
\hline $\begin{array}{l}\langle\text { Phase } 3\rangle \\
\text { A state in which integrated community care providers } \\
\text { are cooperating with each other. }\end{array}$ & $\begin{array}{l}\text { Each organization shares necessary } \\
\text { information and cooperates. }\end{array}$ & $\begin{array}{l}\text { Clarification of information to be shared and } \\
\text { care to be coordinated. } \\
\text { Establish means of cooperation. }\end{array}$ \\
\hline $\begin{array}{l}\text { Phase } 4\rangle \\
\text { A state in which smooth movement is realized and the } \\
\text { patient's intention is reflected. }\end{array}$ & $\begin{array}{l}\text { Establishment of a system that reflects the } \\
\text { wishes of patients. }\end{array}$ & $\begin{array}{l}\text { Establishing care to prevent disability } \\
\text { Establishing care in the event of disability }\end{array}$ \\
\hline
\end{tabular}

As shown in Table 3, we arranged the system into five phases including Phase 0 . We examined the target of each phase and determined the necessary matters for the realization of each target. For example, for "Establishment of a method to understand patient's intention." which is the target of Phase 1, the requirements included 1) an environment that can respect the intention of the patient regarding emergency transportation (of the elderly), and 2) a mechanism that supports the decisions of the patient.

These phases and the necessary requirements will be used to develop specific initiatives in the roadmap.

\subsubsection{Development of initiatives}

It is possible to effectively promote the establishment of the Integrated Community Care System by satisfying the requirement of each phase. This paper shows the way to Phase 4 by materializing the requirements referring to the pioneering cases and matching the initiatives to the topics of the roadmap. The initiatives are shown in Figure 2. 
Total Quality Science Vol.6, No.3

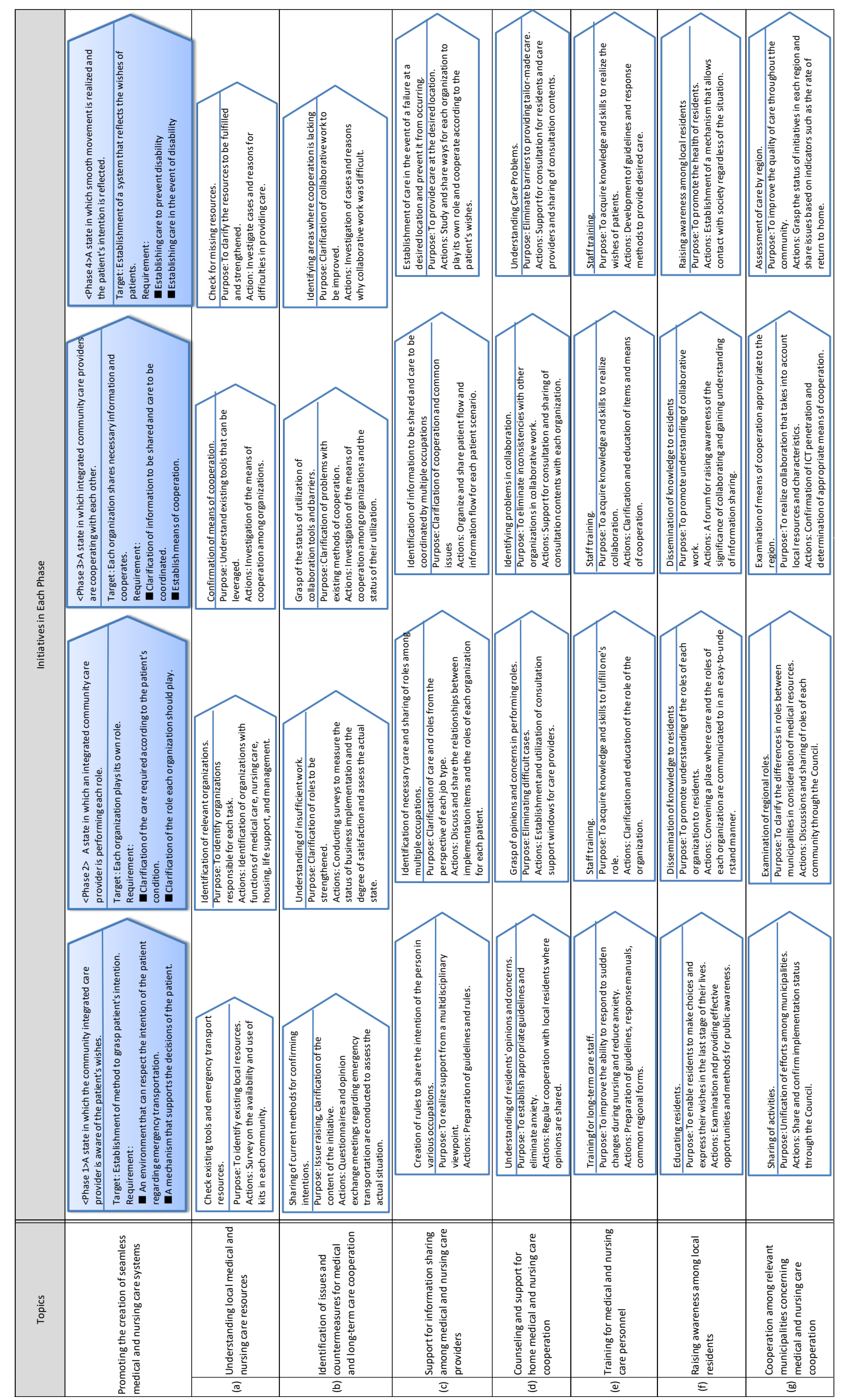

Figure 2: Initiatives developed for each phase 
As shown in Figure 2, initiatives from Phase 1 to Phase 4 are derived. For example, for " $<$ Phase $2>$ The condition in which the integrated community care provider fulfills each role," requirements such as 1 ) clarification of the care required according to the patient's condition, and 2) clarification of the role each organization should play, are specified. In order to satisfy these requirements, first, with respect to understanding resources in (a), the initiative of "Identification of relevant organizations" is derived in order to identify the organizations in the community and clarify the role of each.

These initiatives reflect the matters to be achieved in establishing the Integrated Community Care System, and the perspective on how to achieve them can be examined in the form suitable for each community. Using the roadmap in this fashion, it is possible to examine the concrete initiatives considering the specific situation and objectives of the community.

\subsubsection{Development of specific initiatives}

While the initiatives were developed for each phase, the order relationship had not been sufficiently examined, and it was not clear what kind of initiative should be promoted concretely in Community A. Moreover, as the roadmap shows the matters to be achieved in establishing the Integrated Community Care System, it is necessary to examine how to achieve the initiatives that suit each community. We examined concrete initiatives to introduce in the Community A and the related processes.

As a result of relating the issues in Community A to the roadmap, the dissemination and thoroughness of Advance Care Planning (ACP) was derived as a high-priority initiative. ACP refers to the process in which the patient, family, and health care provider discuss future medical and nursing care, including the terminal stage, in advance and decide on the party responsible for making decisions on behalf of the patient in case the decision making becomes impossible. The execution situation of ACP was investigated in Community A, and using the survey results as a reference, we considered approaches to realize Phase 1 . The roadmap for Phase 1 in Community A is shown in Figure 3. 
Total Quality Science Vol.6, No.3

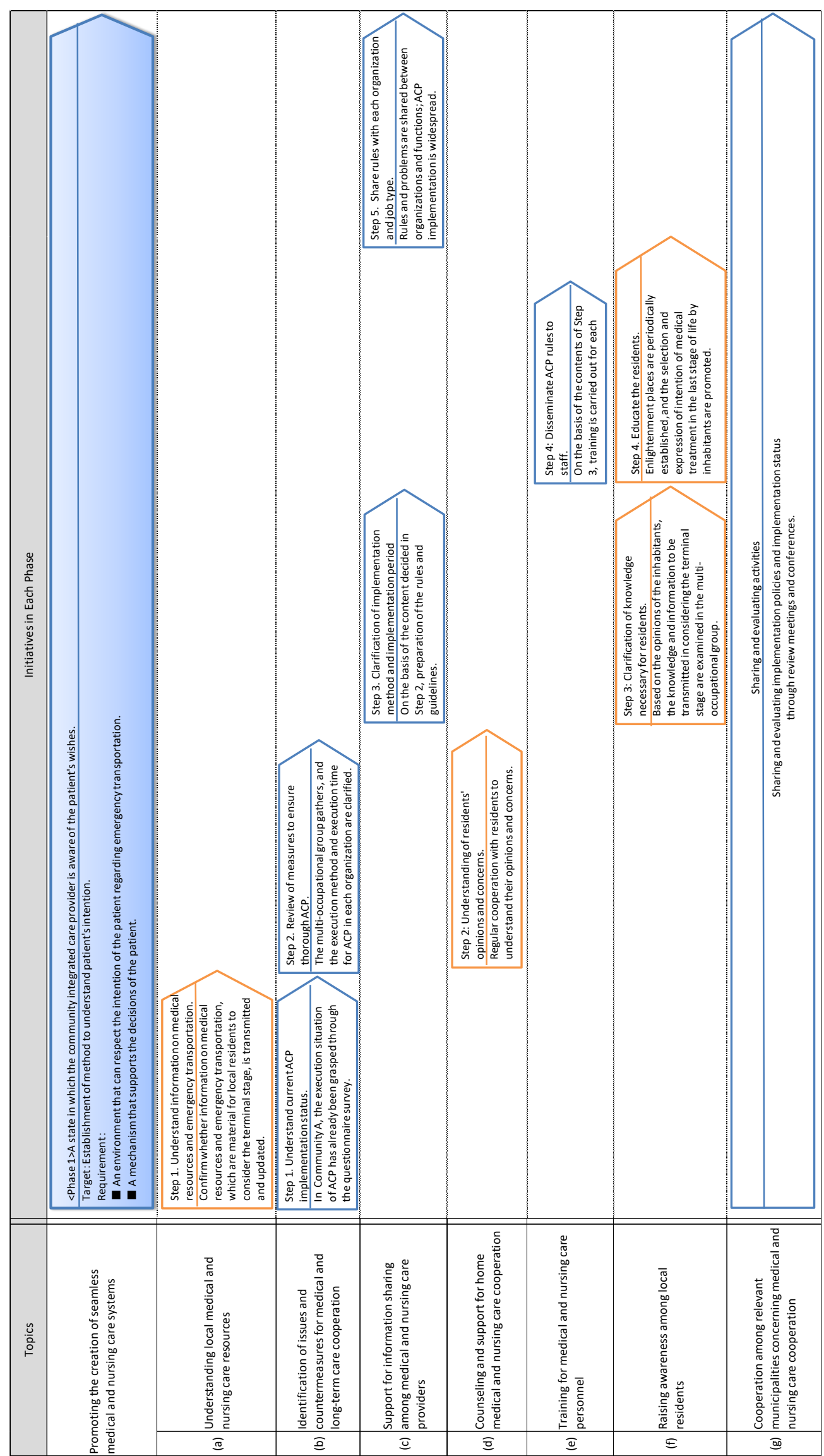

Figure 3: Roadmap of specific initiatives in Community A in Phase 1 
From Figure 3, we have a clearer view on how to approach the achievement of the Phase 1 objectives in Community A. On this basis, we will proceed with the implementation of the initiatives and examination of the later phases.

\section{Proposal of effective method to promote initiatives}

Based on the results of previous studies, we propose the following promotion method using the roadmap approach for the establishment of Integrated Community Care System.

\section{Step 1. Understand the state of the community}

Conduct a questionnaire survey to quantitatively grasp the status of efforts related to the Integrated Community Care System. In this case, the research of YAMAZAKI (2017) on the problem extraction method in the Integrated Community Care System and the research of FURUKAWA et al. (2019) on the design method of the questionnaire survey in the Integrated Community Care System can be referred.

In addition, grasp the status from multiple viewpoints by utilizing the situation of business plans such as regional medical care plans. Then organize the state of the community in order to understand the phase and set the objectives. In this study, we used 8 project items of eight topics from the "Medical Care and Nursing Care Cooperation Promotion Project” as a viewpoint to organize the state of the community.

\section{Step 2. Understand the phases}

In this step, relate the state of the community organized by 8 viewpoints to the phases. At that time, confirm whether the state of the community satisfies the requirement of each phase, and grasp which phase the community is in. The common roadmap shown in Figure 2 may be used to confirm whether initiatives are being made to realize each phase.

\section{Step 3. Set objectives}

The state of the community is arranged based on each viewpoint, and concrete objectives are decided for each. In this case, even if the final ideal state or vague objective is set, it is difficult to lead to the initiatives. Therefore, should be considered by eight viewpoints. Also set up what is feasible based on the initiatives and the requirements of each phase outlined in the common roadmap shown in Figure 2.

\section{Step 4. Extract the priority issue}

Based on the state of the community and the objectives, extract any issues that could be potential barriers to realizing the objective. In this case, it is desirable to examine not only the Priority of issues but also the cause. It is connected with the derivation of the concrete initiatives by considering the countermeasure for removing the cause. And share these with the community.

\section{Step 5. Promote initiatives}

Based on the results of Step 1 to Step 4, derive the initiatives that are prioritized in each community. And consider the process to achieve them. Then develop a roadmap, as shown in Figure 3, which shows the process considered.

Step 6. Implement initiatives 
Share the roadmap developed in Step 5 with the relevant parties. Based on this, examine the role of each organization and each job type, and carry out the initiative. In addition, monitor the progress and measure the effects.

\section{Verification}

\subsection{Application of the proposal method to Community A}

As part of the verification, we first confirmed whether the proposal could be utilized in Community A. This is because the proposal in this study was studied and derived for Community A, so we first conducted verification in this community. The results of applying the proposed method to Region A along each step are presented below.

\section{Step 1. Understand the state of the community}

In Step 1, it is important to have a quantitative understanding of the state of the community. Therefore, we conducted a survey of Community A using a questionnaire designed by YAMAZAKI (2017) and received responses from 262 organizations. By analyzing these responses, we attempted to understand the situation in the region. As a result, the following issues were identified as problems to be addressed in Community A: confirming and respecting the intentions of patients disseminating knowledge about the Integrated Community Care System, strengthening home services, sharing information by multiple professions and building relationships by holding meetings. Thus, the analysis based on the numbers highlighted a specific problem.

\section{Step 2. Understand the phases}

In Step 2, we organize the results identified in Step 1 and identify which phase the region is in by checking that it meets the requirements for each phase listed in Table 3. In doing so, we assigned the specific problems in Community A from the questionnaire survey to each phase. As a result, a number of issues were addressed in Phase 1, including the establishment of a living-will confirmation mechanism. Thus, it is clear that Community A needs to aim for the achievement of Phase 1.

\section{Step 3. Set objectives}

Objectives will be set based on the requirements of the phase. Here, the requirement for Phase 1 is "Establishment of a method to understand patient's intention.”, whereas Community A was not able to know what kind of medical care the patient wanted. Thus, the objective of "clarifying the patient's desired medical care” was established.

\section{Step 4. Extract the priority issue}

In order to realize the objective of Community A defined in Step 3, consider specific issues to be overcome. From Step 1, there was a problem that Community A lacked efforts to confirm, respect, and reflect the intentions of patients and users. In particular, the implementation of the ACP was found to be inadequate. In order to achieve the objective of "clarifying the patient's desired medical care," the priority issue is to "improve the ACP implementation rate." If this issue is resolved, it may lead to the achievement of Phase 1 of the Integrated Community Care System. Therefore, in Community A, it was derived that the "dissemination and thoroughness of ACP” is a priority initiative.

\section{Step 5. Promote initiatives}

It is not immediately possible to disseminate the ACP. It is important to promote the introduction under an appropriate process. Therefore, we have examined the process required to realize the initiative. For example, it 


\begin{abstract}
is known that the rate of implementation of ACP varies among institutions, so it is important to share the perceptions and barriers of the ACP in advance. Therefore, a multi-professional workshop to discuss the ACP was established as a first step. As a result of these processes, the roadmap for promoting the introduction was formulated as shown in Table 4.

Step 6. Implement initiatives

Share the contents of the study up to Step 5 with the conference and other organizations, and the system will be effectively implemented to build the system. In Community A, a conference is held four times a year with representatives from each relevant organization to build the Integrated Community Care System. In the conference, the phases and roadmap presented in this study were presented and consensus was formed. In addition, efforts are being made to "disseminate and thoroughness of ACP" in accordance with the roadmap for promoting the introduction of the ACP.
\end{abstract}

As described above, the process of establishment of the Integrated Community Care System was visualized by proceeding on the basis of the proposal. This study aimed to facilitate "the establishment and sharing of common goals and the creation of concrete plans to achieve them" by visualizing the process. From the above results, it can be seen that a roadmap has actually been developed in Community A and is being used by the conference. Also, the fact that the workshop was held with 100 participants indicates that the establishment activities have moved forward. Therefore, it can be said that the proposed method of this study is useful for visualizing the process and facilitating the initial stage of establishment.

\title{
5.2 Verification of proposal methods by the person in charge of another region
}

While the content of the proposal in this study was examined for Community A, it is a universal promotion method of the establishment of the Integrated Community Care System. Therefore, it is necessary to confirm whether it can be used in other community and whether it is a general method not limited to Community A.

We set up an interview with the person in charge of promoted the Integrated Community Care System in another region (which identify as Community V) to verify the proposal method. At that time, we were asked to confirm the validity of the model, the 56 implementation items in the model, and the initiatives shown in the roadmap. At that time, we asked to confirm that the model, the 56 implementation items in the model, and the initiatives shown in the roadmap are consistent with the actual situation and that there are no omissions. We also received opinions on whether the results of this study are effective in addressing the difficulties in promoting various initiatives in the field. As the result, the following opinions were obtained: (1) the model was visualized and the whole image of the establishment of the Integrated Community Care System was clarified, (2) the common procedure and the region specific procedure were clarified by the roadmap, and the abstraction of the concept and difficulty of the utilization of the pioneering case were eliminated, (3) it can be utilized as a standard in the establishment of the Integrated Community Care System. The above comments confirm the validity of the proposed method.

We need to conduct further verification in the future. "The establishment of the confirmation method of the patient intention" was identified as a priority initiative to be promoted. After this, we will verify whether this is an effective approach.

\section{Discussion}

The Integrated Community Care System is an abstract concept which consists of not only medical treatment but also various elements, and it is difficult to image the completed state. Therefore, it is not easy to set an appropriate goal or to derive an effective approach for establishment. Therefore, there are not many communities where the establishment is smoothly progressing.

In this study, we first considered the community comprehensive care system as a management system. At this time, we noticed that the structure of both of Quality Management System and Integrated Community Care System is similar, and it was possible to consider by replacing "quality of product" and "quality of care". On the other hand, the former generally targets enterprises, while the latter targets regions, and the situation is different in the introduction and operation scenes. Because the chain of command is weak and there are trade-offs between 
organizations, it is difficult for organizations to think for themselves and make their communities better. Therefore, it is important to clarify the common goal and show the concrete process.

In order to promote the establishment of the Integrated Community Care System in consideration of these difficulties, the required activities and a model for its realization were first visualized. Through this, the construction process that was previously vague was made more concrete. In addition, we show the positioning of the conventional research along with clarifying the elements necessary for promoting the initiatives. This became a basis for examining the effectiveness of the tool.

We also examined the phases of the Integrated Community Care System in making the roadmap. By classifying into the phases, the priority issue in promoting the initiatives can be identified. In addition, the route to the final output of "Realization of communities where people can live in their own way" was not clear, and it was difficult to examine how it should be constructed and improved. Then, it is possible to determine the direction to be aimed by subdividing and arranging the ideal state.

Moreover, some pioneering cases have been shown, but these communities do not always consider such phases. For example, even when patient information sharing systems using ICT is introduced in each organization, there may be cases in that the patient's intention is not understood. Systematic promotion is important, and the objective cannot be achieved only by blindly promoting the initiatives.

An Integrated Community Care System is a medical system in which cooperation from the community is especially required, and it is impossible to expand the initiatives of a single hospital within the whole community. In this case, it is necessary to proceed cooperatively from the planning stage, supported by organizational documents. The roadmap proposed in this study provides an opportunity for municipalities to objectively understand their own efforts. In addition, it can be utilized as a communication tool for examining and sharing the objectives of the community in discussions among the different occupations for the preparation of the roadmap.

\section{Conclusions and future study}

In this study, we clarified the activities required for the establishment of the Integrated Community Care System, and examined the proposed model. In addition, the roadmap for promoting the initiatives effectively was developed.

In preparation for future study, it is necessary to promote the implementation of the initiatives in Community A. In that process, we will need to confirm whether the promotion of the initiatives using the roadmap is effective.

\section{References:}

FURUKAWA, S., MUNECHIKA, M., KAJIHARA, C. (2019), “A study on design method of questionnaire survey in Integrated Community Care System”, Total Quality Science, Vol.5, No.3, pp.92-101

Kajihara, C., Kaneko, M., Sano, M., Munechika, M., Sakata, K., Yamamoto, M. (2019), “Development of an Area Disaster Resilience Management System Model for Healthcare”, Journal of social safety science, No.35, pp.67-76

Ministry of Health, Labour and Welfare (2017), "Guidelines for the Medical Care and Nursing Care Cooperation Promotion Project”

Yamamoto, M., Shi, W., Nagai, M., Yokoyama, J. (2014), “A Study of Systematization Policy for Promotion of Cooperation in Construction of Community-Based Integrated Care Systems”, Journal of Japan Management Diagnosis Association, No.14, pp.138-144

YAMAZAKI, S. (2017), "Problem extraction method in constructing an integrated community care system”, the 15th Asian Network for Quality 


\section{Acknowledgements:}

We are grateful to the Community A for collaboration on the whole stages of this work. This study was supported by the Ministry of Education, Culture, Sports, Science and Technology (MEXT) as Private University Research Branding Project.

\section{Author's biographical notes}

Shinki Furukawa graduated the master's course from Waseda University in 2020. He was a student at the Department of Business Design and Management, Graduate School of Creative Science and Engineering, Waseda University, Tokyo, Japan. His research has focused on an Integrated Community Care System. He is a member of the Japanese Society for Quality Control (JSQC).

Chisato Kajihara is a lecturer of Faculty of Informatics, Shizuoka University, Japan. She earned Doctor of Management Engineering from Waseda University in 2013. Her research has focused on Quality Management System (QMS) and Business Continuity Management System (BCMS).

Akira Shindo is a director of Oguno Hospital, Tokyo. He is also a director of Japan Association of Medical and Care Facilities, promoting various efforts to improve the quality of medical care and to establish an Integrated Community Care System. He is a member of the Japanese Society for Quality Control (JSQC).

Masahiko Munechika is a professor in Department of Industrial and Management System Engineering, School of Creative Science and Engineering, Waseda University since 2007. His research has focused on quality management and statistical analysis, including TQM, sentiment quality, healthcare quality, and management diagnosis. He is also a member of Deming Application Prize Committee and Japanese delegate of ISO/TC176.

[DOI : 10.17929/ tqs.6.70]

Received, May 8, 2019

Revised: May 24, 2020

Accepted: September 25, 2020 